\title{
Congenital Dysfibrinogenemia: Fibrinogen Detroit
}

\author{
Eberhard F. Mammen, Ananda S. Prasad, Marion I. Barnhart, and \\ CHI C. Au with the technical assistance of VIRGIL SCHWANDT \\ From the Departments of Physiology and Pharmacology, Pathology and \\ Medicine, Wayne State University, School of Medicine, Detroit, Michigan \\ 48207 and the Veterans Administration Hospital, Allen Park, Michigan 48101
}

A B S T R A C T A 17 yr old female with a congenital
bleeding disorder was found to suffer from dysfibrino-
genemia. Whole blood and plasma coagulation times
were delayed and thrombelastograms were grossly ab-
normal. Clottability of plasma fibrinogen by addition of
thrombin was not demonstrated during the 30 min test
period. Fibrinogen was revealed by turbidometric and
immunologic techniques. Other coagulation factors
were present in normal amounts and prothrombin ac-
tivation was normal. Patient's plasma inhibited throm-
bin clotting times of normal plasma and purified normal
fibrinogen. Fibrinolysis was not detected.

The plasma fibrinogen migrated normally on paper and cellulose acetate electrophoresis, but on immunoelectrophoresis it displayed a faster mobility than normal fibrinogen. On immunodiffusion the antigenic determinants were similar to those of normal fibrinogen. The patient's fibrinogen-antifibrinogen precipitins required longer to appear and the resultant precipitin was broader and hazier than those elicited with normal fibrinogen. These findings suggest the presence of two discrete populations of fibrinogen molecules.

Investigation of the family of the patient suggested that the defect has an autosomal dominant pattern of heredity. Immunologic comparisons of our patient's plasma and of her relatives with plasma of patients with "Fibrinogen Baltimore" and "Fibrinogen Cleveland" revealed certain differences in immunoelectrophoretic mobility as well as in immunodiffusion. In keeping with the nomenclatures of abnormal fibrinogens in the literature, we propose the term "Fibrinogen Detroit" for this fibrinogen.

Physicochemical properties of "Fibrinogen Detroit" were investigated also and compared with those of nor-

This paper was presented by Dr. Prasad at the Meeting of the International Society of Hematology in New York City, 2 September 1968.

Received for publication 29 April 1968 and in revised form 3 September 1968. mal fibrinogen. Purified normal fibrinogen (clottability 96.7\%) and "Fibrinogen Detroit" revealed homogeneity when studied by ultracentrifugation and immunoelectrophoresis. Native and cleaved "Fibrinogen Detroit" had the same sedimentation constants and molecular weights as the normal. In fresh samples, 3 moles of free $\mathrm{SH}$ groups/mole of fibrinogen were titrated in both. Determination of the amino acid composition revealed a decreased content of lysine, glucosamine, and galactosamine in abnormal fibrinogen. Total carbohydrates, protein-bound hexoses, sialic acid, and hexosamine were decreased in the abnormal fibrinogen.

In an investigation with Doctors Blombäck a specific molecular defect was revealed in the $N$-terminal disulfide knot of the alpha (A) chain in which the arginine at the 19th position was replaced by serine. It is believed that the substitution of a strongly basic amino acid with a neutral hydroxy acid may result in considerable conformational changes in the $N$-terminal disulfide knot of fibrinogen which might affect the "active site" for polymerization. The lower carbohydrate content observed in "Fibrinogen Detroit" may have been the result of a change in primary and tertiary structure of the protein.

\section{INTRODUCTION}

A congenital disturbance in the function of fibrinogen seems to be rare. The first patient with dysfibrinogenemia was described in 1958 by Imperato and Dettori (1). This patient suffered from frequent hemorrhages, and the fibrinogen was not readily converted to fibrin. In 1964 Ménaché (2) described a similar congenital fibrinogen abnormality in a patient without a bleeding tendency.

A third family with congenital dysfibrinogenemia was described in 1964 by Beck (3). Several family members were affected and had a mild hemorrhagic tendency. The abnormality seemed to be inherited as a dominant trait. 
Whole blood clotting times were normal, but friable clots were observed. There were electrophoretic differences between the patient's fibrinogen and normal fibrinogen $(4,5)$. In view of certain differences among these patients with dysfibrinogenemia thus far described, Beck and coworkers (3-6) recommended the adoption of a nomenclature similar to the one used for the description of hemoglobinopathies, and termed their abnormal fibrinogen "Fibrinogen Baltimore."

In 1964 von Felten, Duckert, and Frick (7) described a fourth family with an abnormal fibrinogen. A recent reinvestigation of a family previously described as "congenital hypofibrinogenemia" (8) by Beck and Thomas [cited from (6)] revealed that the family suffered from dysfibrinogenemia. The pattern of heredity seemed to be autosomal dominant (8), and the affected family members displayed a mild bleeding tendency. Forman, Boyer, and Ratnoff (9) described the sixth family with an abnormal fibrinogen. The defect seemed to lie in the aggregation of the fibrin monomers. The patient's fibrinogen was distinguishable from normal fibrinogen and "Fibrinogen Baltimore" by immunoelectrophoresis and was termed "Fibrinogen Cleveland."

This report concerns a Detroit Negro family with an abnormal fibrinogen molecule, which we propose to term "Fibrinogen Detroit." Immunological and physicochemical properties of this fibrinogen also are presented in this paper.

Case history. P. H., a 17 yr old Negro female, was admitted to Detroit General Hospital in June 1966 as a referral because of anemia after excessive blood loss during menstruation. Menarche was at age 11. Menstruation was irregular, required use of 7-20 pads a day and flow lasted from 7 to 12 days.

The past history revealed that in July 1965 she was admitted to Detroit General Hospital for the first time on Obstetrics and Gynecology Service because of excessive menstrual bleeding and her hemoglobin was 4.2 $\mathrm{g} / 100 \mathrm{ml}$. Detailed physical and pelvic examinations and routine blood tests failed to reveal any abnormality. No clotting studies were performed at that time. Cervical curettings showed normal secretory endometrium. She was transfused with $4 \mathrm{U}$ of whole blood and on discharge the hemoglobin was $12 \mathrm{~g} / 100 \mathrm{ml}$. She was subsequently seen by Gynecological Service for repeated episodes of anemia after excessive menstrual bleeding for which she received blood transfusions on two different occasions before her admission in June 1966. Because of menstrual difficulties her physician prescribed Norinyl ${ }^{1}$ (progesterone, $1 \mathrm{mg}$, with estrogen ethinyl estradiol 3 methylether $0.05 \mathrm{mg}$ ), 1 tablet daily for 20 days each menstrual cycle. She apparently did fairly well until

\footnotetext{
${ }^{1}$ Syntex Laboratories, Inc., Stanford Industrial Park, Palo Alto, Calif.
}

June 1966 although she had discontinued the hormonal therapy after two months and had failed to return to the clinic.

Family history revealed that her $35 \mathrm{yr}$ old mother (E.H.) also suffered from excessive menstrual bleeding and mild hemorrhages after minor injuries since early childhood. She also gave a history of several episodes of epistaxis. In spite of these bleeding tendencies, she delivered nine children without any serious complications. Two brothers of P. H., one $15 \mathrm{yr}$ old (S. H.) and another $14 \mathrm{yr}$ old (Al. H.) gave history of frequent epistaxis and bleedings after minor cuts. Five other sisters (D. H., An. H., K. H., C. H., and Mo. H.) and one brother (Ma. H.) gave no history of hemorrhagic tendencies.

Physical examination revealed a well-developed and well-nourished female in no acute distress. Except for pallor, no abnormality on physical examination (including pelvic) was noted. Hemoglobin was $8.6 \mathrm{~g} / 100$ ml. Peripheral blood smear revealed normochromic and normocytic anemia. Reticulocyte count was $3.4 \%$. Total leukocyte count and differential counts were within normal limits. Platelet count on admission was $139,000 /$ $\mathrm{mm}^{3}$ and subsequently it was reported to be $216,000 / \mathrm{mm}^{3}$. Serum total protein was $6.9 \mathrm{~g} / 100 \mathrm{ml}$ and protein electrophoresis was unremarkable. Sickle-cell preparation was negative. Other routine laboratory tests such as urinalysis, blood urea nitrogen, fasting blood sugar, and liver function tests were noncontributory. Detailed clotting studies are presented in Table I.

$500 \mathrm{ml}$ of whole blood was withdrawn for isolation and purification of fibrinogen for further studies. Immediately thereafter the patient received $3 \mathrm{U}$ of fresh whole blood and $4 \mathrm{~g}$ of fibrinogen ${ }^{2}$ intravenously. She was then discharged asymptomatic, to be followed in the clinic.

Between June 1966 and February 1968, the patient returned for brief admissions several times because of excessive menstrual bleeding. On each occasion, she responded well to fibrinogen administration (from 4 to $6 \mathrm{~g}$ ) intravenously and 2 to $3 \mathrm{U}$ of fresh whole blood transfusions. Because of recurrent uterine bleeding, total hysterectomy and bilateral wedge resection of ovaries was performed in February 1968. She received $6 \mathrm{~g}$ of fibrinogen the day before surgery. During and after surgery she received a continuous drip of fibrinogen ( 8 $\mathrm{g} /$ day) intravenously for 2 days. She was also transfused with $4 \mathrm{U}$ of fresh whole blood during surgery. She did well postoperatively and has continued asymptomatic.

\section{METHODS}

1. Coagulation studies. Coagulation and fibrinolytic status of the subjects were measured by the following techniques:

${ }^{2}$ Michigan Department of Health, Lansing, Mich. 
Lee and White (10) for clotting time; Duke (11) for bleeding time; Brecher and Cronkite (12) for platelet counts; Howell (13) for recalcification time; Langdell, Wagner and Brinkhous (14) for partial thromboplastin time; Quick (15) for prothrombin time; Ingram and Matchett (16) for thrombin time; Ware and Seegers (17) for prothrombin; Ware and Seegers (18) for ac-globulin; Langdell, Wagner and Brinkhous (19) for factor VIII; Seegers, Miller, Andrews, and Murphy (20) for antithrombin; Ware, Guest and Seegers (21) for clottable fibrinogen by thrombin; Fowell (22) for fibrinogen by turbidometry; Barnhart (23) for fibrinogen by immunological analysis; Seegers, Johnson, and Fell (24) for thrombin titer test; Buckell (25) for euglobin lysis time; Guest (26) for profibrinolysin; Guest, Daly, Ware, and Seegers (27) for antifibrinolysin; Beller, Koch, and Mammen (28) for thromboelastography.

2. Immunologic studies. Antihuman fibrinogen was prepared in rabbits according to Barnhart, Anderson, and Baker (29) by injection of microgram quantities of purified human fibrinogen ( $>96 \%$ clottable and homogeneous according to immunoelectrophoresis against antiplasma). The antiserum obtained had a precipitin titer of $1 / 16384$ against $1 \%$ fibrinogen. This antifibrinogen formed only one precipitin band when reacted against plasma and purified fibrinogen in agar plates and on immunoelectrophoresis. No reaction occurred when this antifibrinogen was tested against purified albumin, prothrombin, profibrinolysin, or gamma globulin IgG $(0.01-1 \%)$.

Quantitative immunoprecipitin assays $(23,30)$ gave a measure of total fibrinogen-related material in plasma and nonclottable fibrinogen-related molecules in serum. An essential feature for accurate determination is excess antibody in the system. Goodman, Wolfe, and Norton (31) established that turbidometric analysis of formed immunoprecipitins was in good agreement with the quantitative precipitin test of Heidelberger and Kendall (32) where the collected antigen-antibody complexes were subjected to nitrogen determination. Our test system is detailed in another publication (30) but the important features are briefly presented here. Nonclottable fibrinogen-related molecules were measured after recalcification or addition of purified thrombin to produce serum. The defibrination phase lasted 30-60 min. Serial dilutions $(1 / 10-1 / 640)$ were prepared from either the serum supernatant or plasma by adding saline (Sherman Laboratories, Detroit, Mich., low particle content). To test tubes containing $4.6 \mathrm{ml}$ saline was added $0.1 \mathrm{ml}$ of the diluted serum or plasma and $0.3 \mathrm{ml}$ of standardized antifibrinogen serum (30). After thorough mixing of the reagents the tube was incubated for $1 \mathrm{hr}$ at $37^{\circ} \mathrm{C}$. The developed turbidity (antigen-antibody complexes) was quantitated with a Turner Nephelometer. Such readings were converted to fibrinogen values by consulting a standard curve prepared from readings obtained when microgram quantities of purified human fibrinogen ( $>96 \%$ clottable) were similarly reacted with antifibrinogen. Appropriate mathematical corrections were made for dilutions. Analysis of the data from the serial dilutions of one specimen revealed those values that reflected quantitative precipitation of the fibrinogen-related molecule. On either side of this region for optimal reactivity, were lower values illustrating incomplete precipitation in antigen excess or insufficient antibody for quantitative precipitation. Plasma fibrinogen values from 15 normals that were run during the same time interval as the present study gave $519 \pm 122 \mathrm{mg} / 100 \mathrm{ml}$. Nonclottable fibrinogen-related molecules in serum of 72 normals stud- ied over the last $5 \mathrm{yr}$ measured $30 \pm 10 \mathrm{mg} / 100 \mathrm{ml}$. These values correspond well with those reported by Schultze and Schwick (33) using a similar turbidometric analysis for quantitative precipitin reactions.

Immunoelectrophoresis was carried out according to the method of Grabar and Williams (34). Double diffusion in agar ran in special Wilson plates (35), or modification of these $(30)$ as comparative analysis or fractional analysis plates (Grabar Corp., Detroit, Mich. ${ }^{8}$ ). Fractional analysis plates consist of several long agar channels in parallel arrangement within one plate for comparison of positioning of an immune complex, rate of development, and concentration dependence under identical environmental conditions.

3. Purification of patient's $(P . H$.$) fibrinogen. The$ fibrinogen from our patient ( $P$. $H$.) and from a normal person was isolated from plasma with a combined ethanol, ammonium sulfate precipitation technique, followed by column chromatography on ion exchange resin Amberlite CG-50, 200-400 mesh. "The total exchange capacity of this resin is $10 \mathrm{meq} / \mathrm{g}$ min. Blood was collected in $3.8 \%$ sodium citrate (one part citrate plus nine parts of blood) and the plasma was separated by centrifugation at $3000 \mathrm{~g}$ for $15 \mathrm{~min}$ at $4^{\circ} \mathrm{C}$ and immediately fractionated. In order to avoid fibrinolysis possibly induced by the addition of ethanol, $1 \mathrm{ml}(5000$ KIU) of Trasylol ${ }^{5}$ was added to both plasmas.

$100 \mathrm{ml}$ of normal or patient's plasma were cooled to $2^{\circ} \mathrm{C}$ and $50 \%$ ethanol was added under stirring to a final ethanol concentration of $16 \%(\mathrm{v} / \mathrm{v})$. After stirring for an additional $15 \mathrm{~min}$ at $2^{\circ} \mathrm{C}$ the mixture was centrifuged at $3000 \mathrm{~g}$ for 15 min at $4^{\circ} \mathrm{C}$. The precipitate was dissolved in $200 \mathrm{ml}$ of $0.9 \%$ $\mathrm{NaCl}$ solution at $37^{\circ} \mathrm{C}$. After complete solution, saturated ammonium sulfate solution was added at $2^{\circ} \mathrm{C}$ under stirring to final concentration of $25 \%(\mathrm{v} / \mathrm{v})$. After stirring for 15 min at $26^{\circ} \mathrm{C}$, the suspension was recentrifuged. The precipitate was once more dissolved in $200 \mathrm{ml}$ of $0.9 \% \mathrm{NaCl}$ solution at $37^{\circ} \mathrm{C}$. The precipitation with ammonium sulfate was repeated once more following the procedure just outlined. The final precipitate was dissolved in $0.9 \% \mathrm{NaCl}$ solution to a total volume of $30 \mathrm{ml}$.

Approximately $100 \mathrm{mg}$ of fibrinogen was placed on each of two Sephadex G-50 ${ }^{\circ}$ columns $(2.5 \times 65 \mathrm{~cm})$ at room temperature previously washed with $0.9 \% \mathrm{NaCl}$ solution. Elution followed with $0.9 \% \mathrm{NaCl}$ solution. Fractions of $12-\mathrm{ml}$ volume were collected. The protein emerged rapidly from the column before the $\left(\mathrm{NH}_{4}\right)_{2} \mathrm{SO}_{4}$ salts were eluted. Protein recovery was around $98 \%$ with both types of fibrinogen. The protein-containing tubes from both columns were combined and freeze-dried.

At this time analytical ultracentrifugation ${ }^{7}$ revealed a minor impurity that migrated slightly faster than the fibrinogen peak. In order to improve the purity, both fibrinogens were chromatographed at room temperature on an ion exchange resin (CG-50) column. Before chromatography, the dried fibrinogen preparations were dissolved in $10 \mathrm{ml}$ distilled water and dialysed for $3 \mathrm{hr}$ at room temperature against 10 liter $0.05 \mathrm{M}$ phosphate buffer, $\mathrm{pH} 7.0$, with three buffer changes. Small amounts of insoluble protein were removed by centrifugation at $3000 \mathrm{~g}$ for $15 \mathrm{~min}$ at $25^{\circ} \mathrm{C}$.

Approximately $100 \mathrm{mg}$ of protein was placed on an ion

${ }^{3}$ P.O. Box 7788, Detroit, Mich.

${ }^{4}$ Mallinckrodt Chem. Works, New York.

${ }^{5}$ Bayer, A. G., Leverkusen, Germany.

- Pharmacia, Uppsala, Sweden.

${ }^{7}$ Beckman Analytical Ultracentrifuge, Spinco Model E, Palo Alto, Calif. 
exchange resin (CG-50) column $(2.5 \times 40 \mathrm{~cm})$ previously washed and equilibrated with $0.05 \mathrm{M}$ phosphate buffer, $\mathrm{pH}$ 7.0. First elution followed with $0.05 \mathrm{~m}$ phosphate buffer, $\mathrm{pH}$ 7.0. The fractions were collected in $12-\mathrm{ml}$ samples. With both, normal and abnormal fibrinogens a small protein peak (about $2 \%$ of the applied protein) emerged with this buffer (Fig. 1), which in the case of the normal fibrinogen did not form fibrin after the addition of thrombin. After having sampled 14 tubes with the $0.05 \mathrm{~m}$ phosphate buffer, $\mathrm{pH} 7.0$, the eluting buffer was changed to $0.3 \mathrm{M}$ phosphate buffer, $\mathrm{pH}$ 7.8 , and $12-\mathrm{ml}$ samples collected. With this buffer the fibrinogen emerged from the column (Fig. 1) and the protein recovery ranged between 90 and $96 \%$.

The protein-containing tubes were combined and saturated ammonium sulfate solution was added to final concentration of $25 \%(\mathrm{v} / \mathrm{v})$ with additional stirring for $15 \mathrm{~min}$ at $2^{\circ} \mathrm{C}$. The suspension was centrifuged at $3000 \mathrm{~g}$ for $15 \mathrm{~min}$ at $4^{\circ} \mathrm{C}$. The precipitate was dissolved in about $8-10 \mathrm{ml}$ of $0.9 \% \mathrm{NaCl}$ solution and dialysed overnight at room temperature against 10 liter of $0.9 \% \mathrm{NaCl}$ solution, frozen in dry ice ethanol, and stored at $-40^{\circ} \mathrm{C}$.

4. Methods employed for investigation of physicochemical properties of fibrinogen. Sedimentation velocity experi-
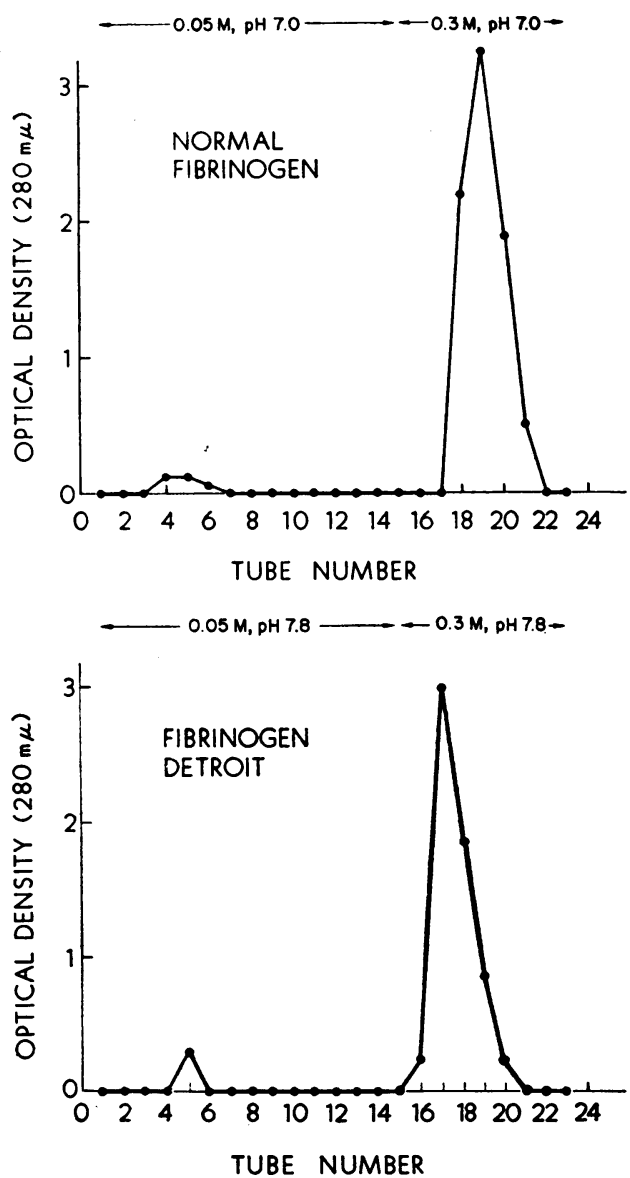

FIgURE 1 This figure shows the chromatographic patterns of normal fibrinogen and Fibrinogen Detroit on ion exchange resin (CG 50). ments were run on the Spinco model E analytical ultracentrifuge using Schlieren optics (36). The S-rates were determined on three dilutions in $0.1 \mathrm{M}$ potassium phosphate buffer, $\mathrm{pH}$ 7.0, and extrapolated to infinite dilution. The sedimentation coefficient was then converted to standard conditions. The meniscus depletion method of Yphantis (37) was used for molecular weight determination. The three dilutions of normal and abnormal fibrinogen in $0.1 \mathrm{M}$ potassium phosphate buffer, $\mathrm{pH} 7.0$, were centrifuged at $12,619 \mathrm{rpm}$ for $18 \mathrm{hr}$ using interference optics for the molecular weight runs. Partial specific volume $(\bar{V})$ of 0.718 was used for calculations (38).

In another experiment, the fibrinogen samples were treated with $5 \mathrm{M}$ guanidine hydrochloride and then dialyzed against $5 \mathrm{M}$ guanidine $\mathrm{HCl}, \mathrm{pH}$ 5.5. Sedimentation velocities and molecular weights were then determined. For the molecular weight determinations, the samples were centrifuged at 15 ,$220 \mathrm{rpm}$ for $13 \mathrm{hr}$ with interference optics. A partial specific volume $(\bar{V})$ of 0.696 was used for calculations $(38)$. In order to study the subunits of fibrinogens, following denaturation in $5 \mathrm{M}$ guanidine $\mathrm{HCl}$, cleavage with sodium sulfite was accomplished according to the method of Johnson and Mihalyi (38) and sedimentation velocities and molecular weights were determined in these samples. For molecular weight determinations, the samples were centrifuged at $32,603 \mathrm{rpm}$ for $9 \mathrm{hr}$ with interference optics and a partial specific volume $(\overline{\mathrm{V}})$ of 0.688 was used for calculations (38).

In freshly purified fibrinogen samples, free $\mathrm{SH}$ groups were amperometrically titrated according to the methods published before $(39,40)$. The amino acid analysis was performed according to the methods of Spackman, Stein and Moore (41) after hydrolysis for $22 \mathrm{hr}$. Protein-bound hexoses were measured by the method of Mokrasch (42) and hexosamine was determined by the method of Rimington (43). Sialic acid was measured by the method of Ayala Moore, and Hess (44). Protein content was determined by the micro-Kjeldahl method (45).

Polypeptide mapping of alpha (A) chain of the $N$-terminal fragments from normal and patient's fibrinogen were accomplished by the methods of Blombäck et al. $(46,47)$.

\section{RESULTS}

1. Coagulation and immunologic studies in the patient $(P . H$.$) . The whole blood clotting time of the patient$ (P. H.) was repeatedly around $26 \mathrm{~min}$. The formed clots initially friable became firm upon storage for several additional hours at $37^{\circ} \mathrm{C}$ and retracted normally. The bleeding time was $31 / 2 \mathrm{~min}$.

The plasma coagulation time, recalcification time, partial thromboplastin time, prothrombin time, and thrombin time were grossly prolonged, but normal levels of prothrombin, Ac-globulin, factor VIII, and antithrombin were found (Table I). Euglobulin lysis time was normal. The level of profibrinolysin was $195 \mathrm{cU} / \mathrm{ml}$ (control $207 \mathrm{cU} / \mathrm{ml}$ ) and the level of antifibrinolysin was $162 \mathrm{U} / \mathrm{ml}$ (control $176 \mathrm{U} / \mathrm{ml}$ ). The patient's plasma clot was insoluble in $5 \mathrm{~m}$ urea solution.

No clottable fibrinogen could be determined in the patient's plasma with the method employed. Turbidometric measurements revealed $300 \mathrm{mg} / 100 \mathrm{ml}$ fibrinogen in the patient's plasma, and the quantitative immunological 
TABLE I

Some Plasma Coagulation Studies on Patient P. H. and Members of Her Family

\begin{tabular}{|c|c|c|c|c|c|c|c|c|c|c|}
\hline & $\begin{array}{c}\text { Recalci- } \\
\text { fication } \\
\text { times of } \\
\text { plasma } \\
(13)\end{array}$ & $\begin{array}{c}\text { Partial } \\
\text { thrombo- } \\
\text { plastin } \\
\text { times } \\
(14)\end{array}$ & $\begin{array}{l}\text { Pro- } \\
\text { thrombin } \\
\text { times } \\
(15)\end{array}$ & $\begin{array}{l}\text { Prothrombin, } \\
\text { 2-stage } \\
\text { (17) }\end{array}$ & $\begin{array}{c}\text { Ac- } \\
\text { globulin } \\
\text { (factor } \\
\text { V) } \\
(18)\end{array}$ & $\begin{array}{l}\text { Factor } \\
\text { VIII } \\
\text { (19) }\end{array}$ & $\begin{array}{l}\text { Fibrinogen } \\
\quad(21)\end{array}$ & $\begin{array}{c}\text { Euglobulin } \\
\text { lysis } \\
\text { times } \\
(25)\end{array}$ & $\begin{array}{l}\text { Thrombin } \\
\text { times } \\
(16)\end{array}$ & $\begin{array}{l}\text { Anti- } \\
\text { thrombin } \\
(20)\end{array}$ \\
\hline & sec & $\sec$ & sec & $U / m l$ & $U / m l$ & $\%$ & $\mathrm{mg} / 100 \mathrm{ml}$ & $\min$ & sec & $\%$ \\
\hline P. H. & $>600$ & $>600$ & $>30$ & 211 & 17.6 & 175 & 0 & $>180$ & $>60$ & 52 \\
\hline E. H. & 141 & 63 & 12.6 & 220 & 18.6 & 100 & 124 & $>180$ & $>60$ & 61 \\
\hline S. H. & 138 & 69 & 15.7 & 198 & 16.2 & 98 & 96 & $>180$ & $>60$ & 42 \\
\hline Al. $\mathrm{H}$. & 151 & 68 & 12.6 & 236 & 14.8 & 76 & 87 & $>180$ & $>60$ & 48 \\
\hline Mo. H. & $>600$ & $>600$ & $>30$ & 218 & 17.2 & 124 & 0 & $>180$ & $>60$ & 46 \\
\hline D. H. & 98 & 68 & 14.3 & 246 & 16.9 & 84 & 244 & $>180$ & 15.1 & 51 \\
\hline An. $\mathrm{H}$. & 103 & 61 & 12.6 & 235 & 15.8 & 112 & 247 & $>180$ & 14.8 & 59 \\
\hline K. H. & 89 & 55 & 12.9 & 261 & 17.2 & 138 & 242 & $>180$ & 14.6 & 42 \\
\hline C. $\mathrm{H}$. & 122 & 60 & 12.7 & 219 & 16.2 & 95 & 196 & $>180$ & 14.3 & 51 \\
\hline Ma. H. & 114 & 65 & 12.7 & 241 & 15.4 & 106 & 244 & $>180$ & 15.6 & 53 \\
\hline Normal & $80-120$ & $50-70$ & 12.6 & $250 \pm 50$ & 17.2 & $60-200$ & $200-300$ & $>180$ & 14.5 & $40-60$ \\
\hline
\end{tabular}

analysis of the fibrinogen related molecules in plasma gave $960 \mathrm{mg} / 100 \mathrm{ml}$. The determination of fibrinogenrelated molecules in the patient's serum gave $160 \mathrm{mg} / 100$ $\mathrm{ml}$. The presence of fibrinogen in plasma could further be demonstrated by means of paper electrophoresis and cellulose acetate electrophoresis without a migration rate different from normal.

The thrombin titer tests on patient's plasma and normal plasma gave similar curves (Fig. 2) indicating a normal rapid conversion of prothrombin to thrombin. The addition of normal human or bovine fibrinogen to the patient's plasma resulted in normal plasma recalcification time, partial thromboplastin time, and prothrombin time, further evidence that there was no disturbance in the activation of prothrombin to thrombin. But the clotting time for normal plasma or normal human fibrinogen by thrombin was inhibited by the addition of patient's plasma (Table II). Added calcium did not im-

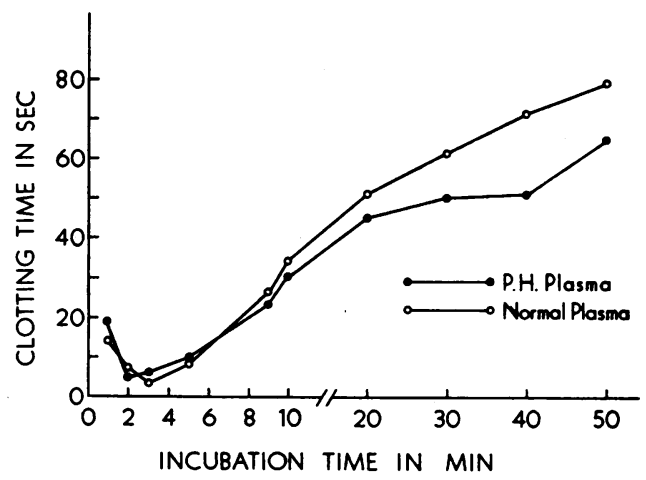

FIgURE 2 Thrombin titer test on normal plasma and the patient's (P. H.) plasma. prove the clotting of the patient's fibrinogen by thrombin (Table II).

The plasma thrombelastogram tracings of the patient were grossly abnormal (Fig. 3). The reaction times ( $r$-times) were $20 \mathrm{~min}, 30 \mathrm{sec}$ (normal : $4 \mathrm{~min}-6 \mathrm{~min}, 30$ sec) and thrombus formation times ( $k$-times) were 142 min (normal: $1 \mathrm{~min}-2 \mathrm{~min}, 30 \mathrm{sec}$ ). The amplitudes (deflection) of the thrombelastograms never reached a normal maximum $\left(m_{\epsilon}\right)$. Over a period of $7 \mathrm{hr}$ a continuous increase of amplitude to $44 m_{\epsilon}$ (normal 150-350 $m_{\epsilon}$ ) was observed. In normal thrombelastogram the maximum amplitude $\left(m_{\epsilon}\right)$ is usually reached between $1 / 2-1 \mathrm{hr}$ with a decreased amplitude following.

Immunologic testing of the patient's plasma fibrinogen presented certain unique features. A considerable amount of the fibrinogen-related molecules had a faster mobility than normal plasma fibrinogen on agar immunoelectrophoresis. The precipitin line formed principally in the region of alpha proteins to contrast with the beta-oriented arc formed by normal plasma fibrinogen (Fig. 4). Also the precipitin band formed was less dense than the normal fibrinogen-antifibrinogen arc. On double diffusion in agar the patient's fibrinogen-antifibrinogen band was delayed in appearance, broader, and hazier than the normal to suggest two discrete populations of fibrinogen-related molecules (Fig. 5). Neither complete intersection of precipitin lines nor spur formation occurred, but a region of low density or hazy interaction connected the patient's precipitin band with that of normal plasma. The interpretation that patient's fibrinogen and normal fibrinogen have in common a few, but not all, antigenic determinant groups seems reasonable from these data.

2. Coagulation and immunologic studies in family mem- 
TABLE II

Effect of Normal Plasma, Normal Human Fibrinogen, and Calcium on Thrombin Clotting Times of Patient's Plasma

\begin{tabular}{|c|c|c|}
\hline \multirow[t]{2}{*}{ Thrombin time } & \multicolumn{2}{|c|}{$\begin{array}{l}(0.2 \mathrm{ml}) \text { Plasma } \\
(0.1 \mathrm{ml}) \text { Thrombin, } 100 \mathrm{U} / \mathrm{ml} \text {, with or with- } \\
\text { out } \mathrm{CaCl}_{2}(0.025 \mathrm{M})\end{array}$} \\
\hline & & $\begin{array}{l}\text { Clotting } \\
\text { times }\end{array}$ \\
\hline & & sec \\
\hline \multicolumn{2}{|c|}{ Normal plasma $(0.2 \mathrm{ml})$} & 20.9 \\
\hline \multicolumn{2}{|c|}{ Patient's plasma $(0.2 \mathrm{ml})$} & $>60$ \\
\hline \multicolumn{2}{|c|}{$\begin{array}{l}\text { Normal plasma }(0.1 \mathrm{ml}) \text { plus } \\
\text { patient's plasma }(0.1 \mathrm{ml})\end{array}$} & 37.1 \\
\hline \multicolumn{2}{|c|}{$\begin{array}{l}\text { Normal plasma }(0.1 \mathrm{ml}) \text { plus } \\
\quad \text { human fibrinogen, } 0.25 \mathrm{mg},(0.1 \mathrm{ml})\end{array}$} & 14.3 \\
\hline \multicolumn{2}{|c|}{$\begin{array}{l}\text { Patient's plasma }(0.1 \mathrm{ml}) \text { plus } \\
\text { human fibrinogen, } 0.25 \mathrm{mg},(0.1 \mathrm{ml})\end{array}$} & 24.6 \\
\hline \multirow{2}{*}{\multicolumn{2}{|c|}{$\begin{array}{l}\text { Normal plasma }(0.2 \mathrm{ml}) \text { plus } \mathrm{CaCl}_{2} \\
\text { Patient's plasma }(0.2 \mathrm{ml}) \text { plus } \mathrm{CaCl}_{2}\end{array}$}} & 19.5 \\
\hline & & $>60$ \\
\hline
\end{tabular}

bers. The results of most of the coagulation studies are listed in Tables I and III. The investigations revealed that a $4 \mathrm{yr}$ old sister (Mo. H.) of our patient had an identical coagulation defect. The thrombelastographic pattern was also identical to our patient $\mathrm{P}$. $\mathrm{H}$. The $r$-times were prolonged $(17 \mathrm{~min}, 45 \mathrm{sec})$, the $k$-times were grossly abnormal ( $84 \mathrm{~min})$, and the amplitudes never reached a maximum (amplitude after $4 \mathrm{hr}$ was $41 m_{\epsilon}$ ). The immunoelectrophoretic characteristics of Mo. $\mathrm{H}$. were similar to $\mathrm{P}$. $\mathrm{H}$. with a weak precipitation reaction in the region of the alpha globulins. On immunodiffusion, the plasma of Mo. $\mathrm{H}$. formed a single precipitin line with antifibrinogen antisera, which formed a line of identity with normal plasma as well as the plasma of P. H.

Of further interest were the coagulation studies on the mother (E. H.) and two brothers, S. H. and Al. H., who gave a history of bleeding. Their plasma recalcification time was slightly prolonged (Table I), whereas the partial thromboplastin time was within normal range. The prothrombin times of E. H. and Al. H. were normal, but that of S. H. was prolonged. The thrombin time of all three was grossly abnormal. Determinations of fibrinogen by the clotting procedure revealed decreased plasma fibrinogen for all three, whereas turbidometric and immunologic procedures gave higher levels of fibrinogen (Table III). This suggests that these three relatives had only partially clottable fibrinogen molecules. The other coagulation factors were normal.

Thrombelastography of E. H., Al. H., and S. H. gave abnormal patterns, too. The $r$-times of the three patients were normal, but the $k$-times were grossly abnormal. The $k$-time was $14 \mathrm{~min}$ for E. H.; $41 \mathrm{~min}, 30 \mathrm{sec}$ for S. H.; and for Al. H., 53 min, $45 \mathrm{sec}$ (normal: 1 min$2 \mathrm{~min}, 30 \mathrm{sec}$ ). The amplitudes of these three family members resembled those of $\mathrm{P} . \mathrm{H}$. and $\mathrm{Mo}$. $\mathrm{H}$. as a continuous increase in amplitude occurred without reaching a maximum period of $7 \mathrm{hr}$ when the amplitude $\left(m_{\epsilon}\right)$ for E. H. was 96 ; for S. H. 41 ; and for Al. H. 38.

Based on the coagulation data (abnormal thrombin times, low levels of clottable fibrinogen and abnormal thrombelastograms) associated with a bleeding tendency, we assume that the mother of our patient and her two brothers have partially normal and partially abnormal fibrinogen, whereas another sister (Mo. H.) has only abnormal fibrinogen molecules.

Immunoelectrophoresis on plasma from the two affected brothers and the mother gave similar patterns to P. H. They also required more time than normal for precipitin band formation in double diffusion plates. Plasma of both the mother and Al. $\mathrm{H}$. revealed precipitin bands with indistinct areas, suggesting two populations of fibrinogen-related molecules, but these were much slower in development than in the patient (Fig. 6). S. H. presented the most compact precipitin of these affected family members.

Immunologic analysis of plasma from the remaining family members revealed that all had weaker precipitin lines formed in the alpha protein region to contrast with the more dense beta protein band formed by normal plasma. When cross-reacted in double diffusion systems with antifibrinogen, all of the family members showed correspondence of antigenic determinant groups with complete fusion of the precipitin bands and identification

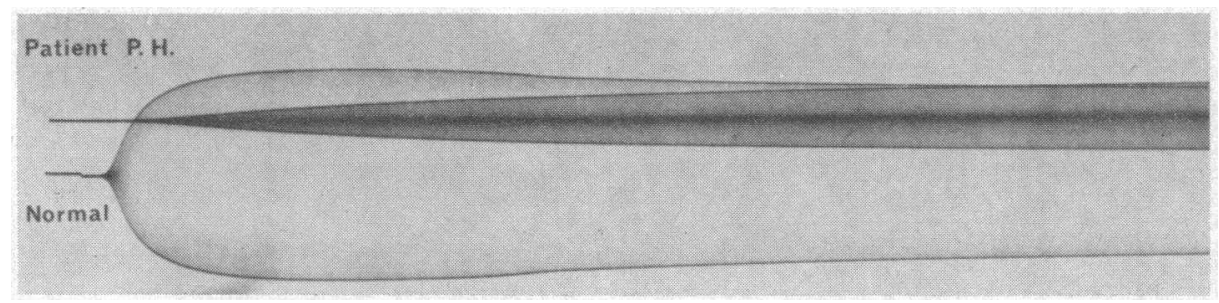

FIGURE 3 Plasma thrombelastogram of the patient's plasma (P. H.) and normal plasma. Both plasmas were platelet-rich. 


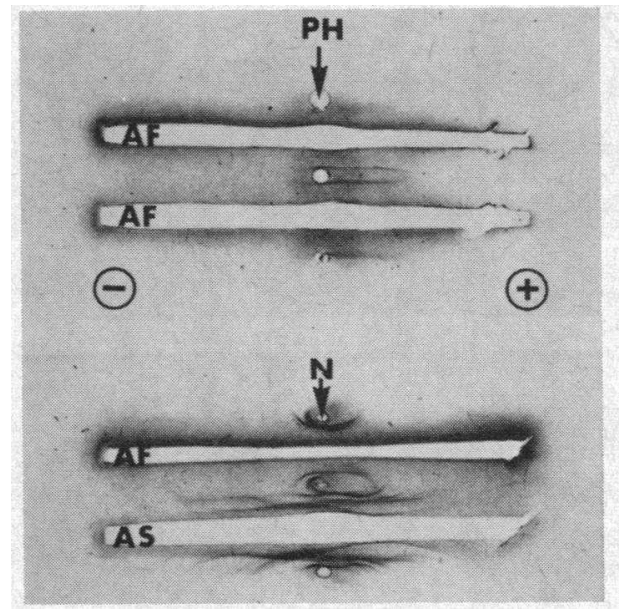

FIGURE 4 Immunoelectrophoresis of normal plasma $(N)$ and the patient's $(P H) . A F$ is rabbit antifibrinogen No. 582. $A S$ is antiserum (Hyland IEP serum).

with normal plasma fibrinogen without spur formations. The abnormality of the patient's fibrinogen was especially prominent when immunodiffusion was run in fractional analysis plates. The patient had a much broader reacting band than any other family member. This band formed rather near to the antifibrinogen well in contrast to the centrally positioned and more compact bands of the other family members.

The other members of the family (D. H., An. H., K. H., C. H., and Ma. H.) have no hemorrhagic tendency; they had normal coagulation values, normal levels of fibrinogen (Table I), and normal thrombelastograms.

3. Immunologic comparison of "Fibrinogen Detroit" with "Fibrinogen Baltimore" and "Fibrinogen Cleveland." An immunologic comparison (Table IV) was made between the reactivity of the Detroit family, the Cleveland family (samples provided by Dr. W. B. Forman), the Baltimore patient (samples provided by Dr. D. P. Jackson), and normal plasma reacted with antifibrinogen. All had some antigenic determinant groups in common as cross reactions occurred in double diffusion experiments (Fig. 7). However, Detroit P. H.

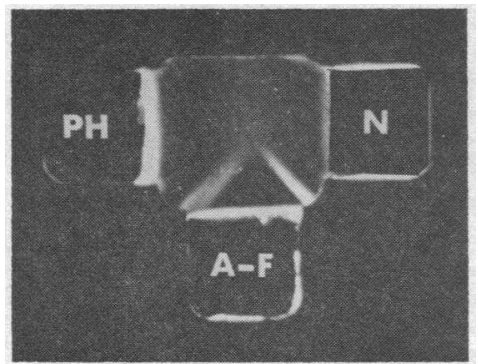

FIGURE 5 Double diffusion in agar of normal plasma $(N)$ and the patient's plasma $(P H)$ against antifibrinogen No. $755(A-F)$.
TABLE III

Comparative Fibrinogen Determinations in the Five Family Members with Bleeding Tendencies

\begin{tabular}{|c|c|c|c|}
\hline & \multicolumn{3}{|c|}{ Fibrinogen determinations in plasma } \\
\hline & $\begin{array}{l}\text { Clotting } \\
\text { procedure } \\
(21)\end{array}$ & $\begin{array}{l}\text { Turbido- } \\
\text { metric } \\
\text { procedure } \\
(22)\end{array}$ & $\begin{array}{l}\text { Immunologic } \\
\text { procedure } \\
\text { (23) }\end{array}$ \\
\hline & \multicolumn{3}{|c|}{$\mathrm{mg} / 100 \mathrm{ml}$} \\
\hline P. H. & 0 & 300 & 960 \\
\hline Mo. H. & 0 & 296 & 600 \\
\hline E. H. & 124 & 312 & 720 \\
\hline S. H. & 96 & 247 & 880 \\
\hline Al. H. & 87 & 235 & 670 \\
\hline Normal & $200-300$ & $200-350$ & $519 \pm 122$ \\
\hline
\end{tabular}

and $\mathrm{E} . \mathrm{H}$. and the Baltimore patient had fewer than the normal number of accessible reactive groups in their plasma fibrinogens, as a spur precipitin protruded beyond the area of fusion between patient and the normal precipitin. Such spurring could be accentuated by appropriate changes in concentration of purified fibrinogen. All formed weaker precipitin bands than the normal fibrinogen-antifibrinogen complex. The Cleveland family formed more dense precipitins than did the Detroit family and the Baltimore patient gave the weakest reaction of all. The Cleveland mother formed a precipitin band as fast as normal, whereas the Detroit family had delayed fibrinogen-antifibrinogen complexes with this mother also showing the most dense precipitin. Three members of the Detroit family (P. H., Al. H., and E. H.) and the Cleveland patient showed subdivisions in their broad precipitin bands. All except $\mathrm{P}$. $\mathrm{H}$. had delayed reactions. All the other family members and normal plasma

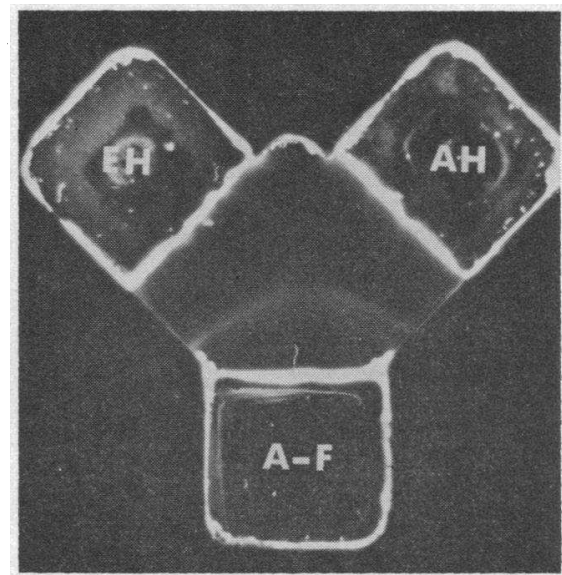

Figure 6 Double diffusion in agar of plasma from the patient's mother $(E H)$ and $14 \mathrm{yr}$ old brother $(A H)$ against antifibrinogen $(A-F)$ No. 755.

Fibrinogen Detroit 
TABLE IV

Comparison of Immunologic Features of Dysfibrinogenemia Families

\begin{tabular}{|c|c|c|c|c|}
\hline \multirow[b]{2}{*}{ Subjects } & \multirow[b]{2}{*}{$\begin{array}{l}\text { Immunoelectrophoresis } \\
\text { fibrinogen reactants } \ddagger\end{array}$} & \multicolumn{3}{|c|}{ Immunodiffusion* } \\
\hline & & $\begin{array}{l}\text { Fibrinogen } \\
\text { populations§ }\end{array}$ & Intensity\| & Cross-reactions $\llbracket$ \\
\hline \multicolumn{5}{|l|}{ Detroit (D) } \\
\hline P. H. (patient) & $\alpha \alpha \alpha \beta$ & 2 & ++ & $\mathrm{D}, \mathrm{C}, \mathrm{B}, \mathrm{N}$ \\
\hline Mo. H. & $\alpha \alpha \beta \beta$ & 1 & ++ & $\mathrm{D}, \mathrm{C}, \mathrm{N}$ \\
\hline Al. H. & $\alpha \alpha \beta \beta$ & 2 & ++ & $\mathrm{D}, \mathrm{B}, \mathrm{N}$ \\
\hline S. H. & $\alpha \alpha \beta \beta$ & 1 & $+t$ & $\mathrm{D}, \mathrm{N}$ \\
\hline Ma. H. & $\alpha \alpha \beta B$ & 1 & +++ & $\mathrm{D}, \mathrm{N}$ \\
\hline K. H. & $\alpha \alpha \alpha \beta$ & 1 & +++ & $\mathrm{D}, \mathrm{N}$ \\
\hline C. $\mathrm{H}$. & $\alpha \alpha \alpha \beta$ & 1 . & +++ & $\mathrm{D}, \mathrm{N}$ \\
\hline Am. $\mathrm{H}$. & $\alpha \alpha \alpha \beta$ & 1 & $+t+$ & $\mathrm{D}, \mathrm{N}$ \\
\hline D. H. & $\alpha \alpha \alpha \beta$ & 1 & +++ & $\mathrm{D}, \mathrm{N}$ \\
\hline E. H. & $\alpha \alpha \alpha \beta$ & 2 & +++ & $\mathrm{D}, \mathrm{C}, \mathrm{B}, \mathrm{N}$ \\
\hline \multicolumn{5}{|l|}{ Cleveland (C) } \\
\hline Patient & $\alpha B B \beta$ & $1-2$ & +++ & P. H., Mo. H., N \\
\hline Sister & $\alpha \beta \beta \beta$ & $1-2$ & +++ & P. H., Mo. H., N \\
\hline Mother & $\beta_{i} \beta \beta \beta$ & 1 & +++ & $\mathrm{D}, \mathrm{B}, \mathrm{N}$ \\
\hline \multicolumn{5}{|l|}{ Baltimore (B) } \\
\hline Patient & $\alpha \beta \beta \beta$ & 1 & + & $\mathrm{D}, \mathrm{C}_{\mathrm{m}}, \mathrm{N}$ \\
\hline Normal (N) & $\beta \beta \beta \beta$ & 1 & ++++ & $\mathrm{D}, \mathrm{C}, \mathrm{B}, \mathrm{N}$ \\
\hline
\end{tabular}

* Electrophoresis for $30 \mathrm{~min}$ at $40 \mathrm{v}$, equivalent to $6 \mathrm{v} / \mathrm{cm}$.

$\ddagger$ Normal plasma fibrinogen forms a precipitin arc centered over the point of application; the designation $\beta \beta \beta \beta$ indicates all fibrinogen molecules remain there. Introduction of the $\alpha$ symbol indicates the relative proportion of fibrinogen-related molecules with faster mobilities than normal fibrinogen.

\$ Incomplete separation of precipitin band suggests two populations of fibrinogen reactants.

\| Visual judgement of density of precipitin bands. The normal compact fibrinogen-antifibrinogen complex is graded at $4+$ with $1+$ indicating a faint reaction.

I Capital letters refer to different families or family members tested for common antigenic determinants in their fibrinogens.
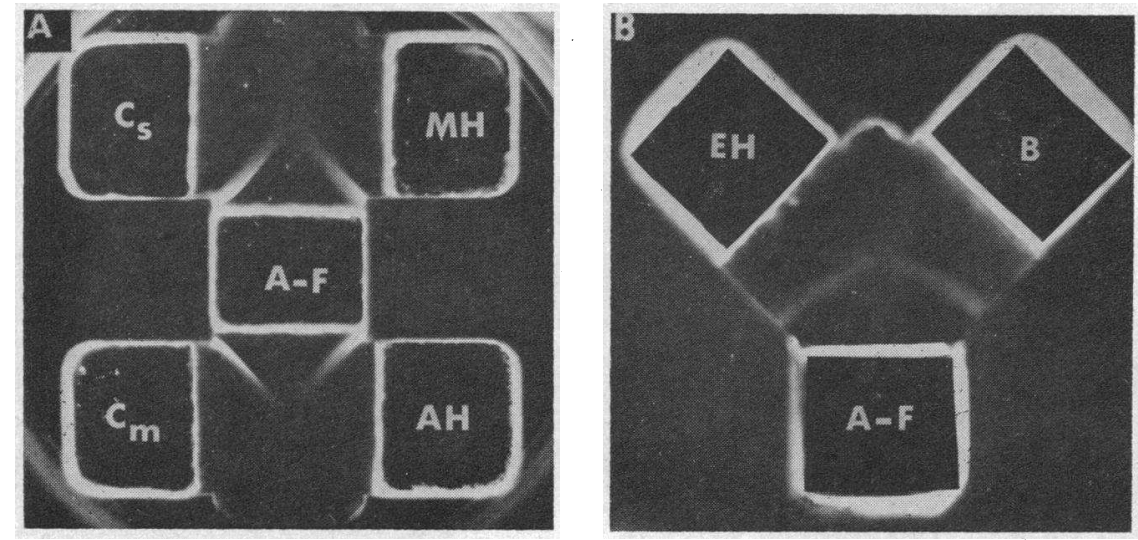

FIGURE 7 Immunologic comparison of the reactivity of fibrinogen of the Detroit family, the Cleveland family, and the Baltimore patient with antifibrinogen $(A-F)$ No. 618 with double diffusion technic. $8 \mathrm{~A}$ : comparison of Cleveland patient $\left(C_{\mathrm{s}}\right)$ with Detroit patient Mo. H. $(M H)$ and Cleveland mother $\left(C_{m}\right)$ with the brother $A l . H .(A H)$ of Detroit patient P.H. $8 \mathrm{~B}$ : comparison of Detroit mother $(E H)$ with Baltimore patient $(B)$. 

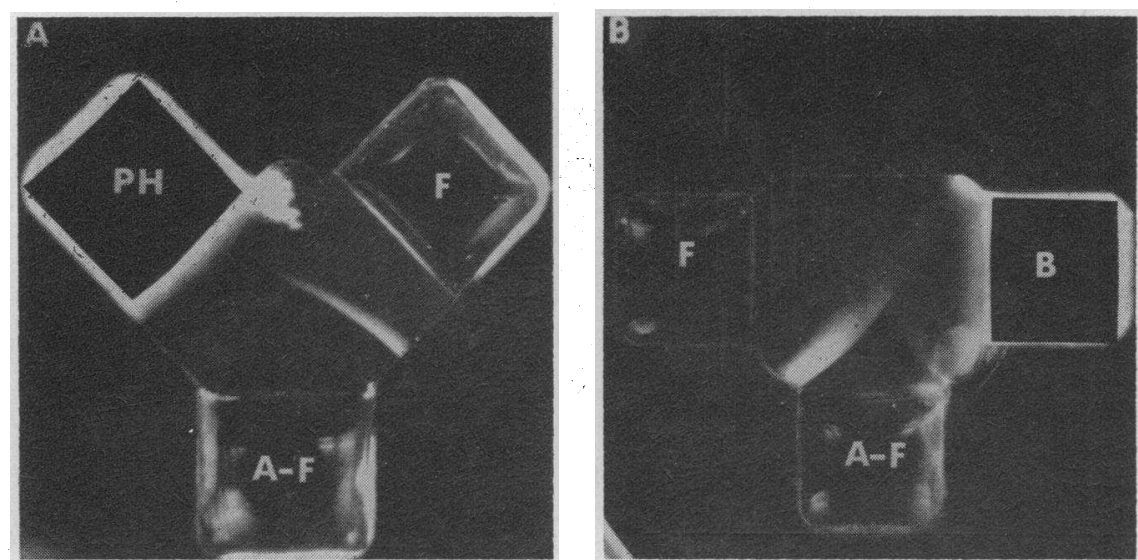

FIGURE 8 A : immunologic comparison of Detroit patient's $(P H)$ plasma fibrinogen with purified normal human fibrinogen $(F)(2.7 \mathrm{mg})$ with double diffusion technic and antifibrinogen No. $755(A-F)$. B : comparison of purified normal human fibrinogen $(F)(2.7 \mathrm{mg})$ with plasma fibrinogen of Baltimore $(B)$ patient. Antifibrinogen $(A-F)$ No. 755.

had only one compact band for the immune complex. Mixing of Detroit P. H., Al. H., S. H., or E. H. with either Baltimore plasma or normal plasma before double diffusion did not accentuate or alter the precipitin bands. The Detroit members with coagulation abnormalities and the Baltimore patient formed precipitins that only partially identified with purified normal fibrinogen (Fig. 8). All subjects tested here had faster (alpha) mobility fibrinogen-like molecules on immunoelectrophoresis than did normals or purified fibrinogen which retained its beta position at the application point. The greatest amount of fast mobility plasma fibrinogen occurred in the Detroit family with the two boys (S. H., Al. H.) and the youngest girl (Mo. H.), who retained more nearly the normal position. All of the Detroit family had more alpha components than did the Cleveland patient and sister who had more than the Baltimore patient, whose precipitin line formed essentially in the normal beta position. The Cleveland mother did not differ from normal plasma fibrinogen with reactants remaining centered about the application point.

4. Physicochemical properties of "Fibrinogen Detroit." Normal purified fibrinogen had a clottability of $96.7 \%$. The patient's fibrinogen was only slowly reactive to thrombin but clotted eventually after several $\mathrm{hr}$ of incubation at $37^{\circ} \mathrm{C}$. A homogeneous pattern for both fibrinogens was seen in the analytical ultracentrifuge and the sedimentation constants $\left(s^{\circ}{ }_{20, \mathrm{w}}\right)$ in $0.1 \mathrm{M}$ potassium phosphate buffer, $\mathrm{pH} 7.0$, were 7.41 for both samples (Fig. 9). A mol wet ( $\overline{\mathrm{M}}_{N}$ average) of $292,034 \pm 21,995$ (SD) was calculated for normal fibrinogen (concentration, $0.0635 \mathrm{~g} / 100 \mathrm{ml}$ ) and for the patient's fibrinogen (concentration, $0.095 \mathrm{~g} / 100 \mathrm{ml}$ ) $\overline{\mathrm{M}}_{N}$ average of 309,065 $\pm 10,416$ (SD) was obtained. On extrapolation to zero

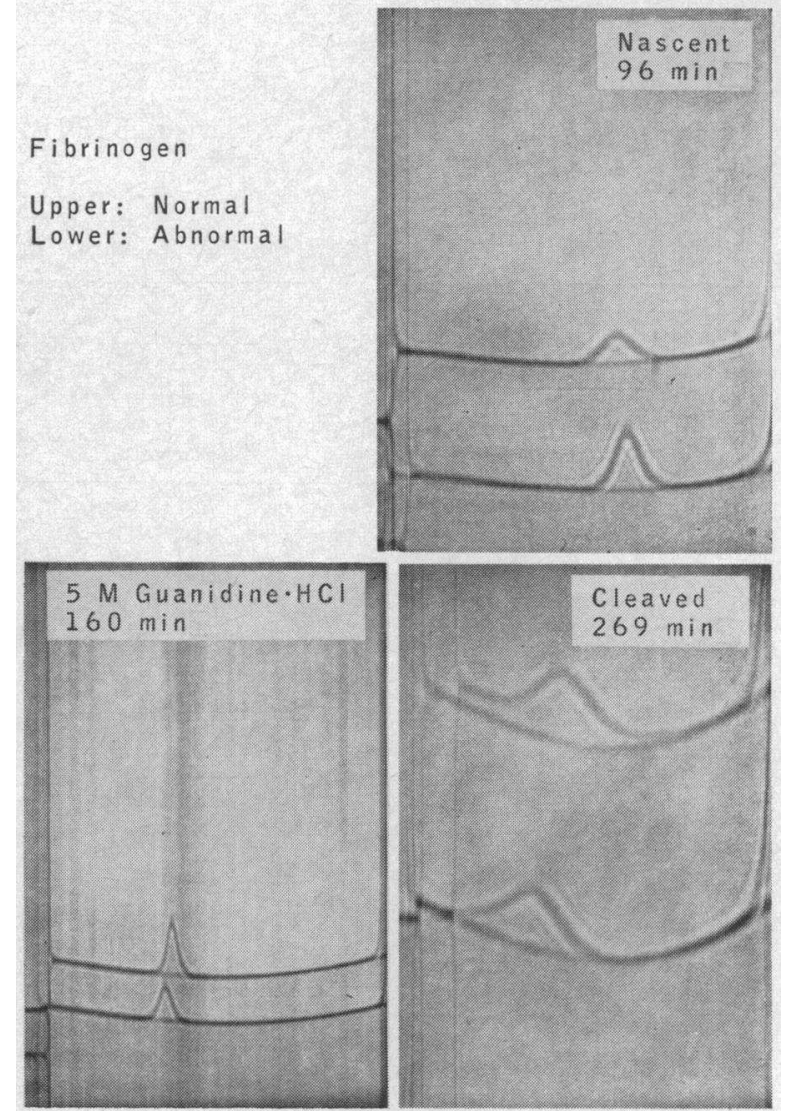

Figure 9 The analytical ultracentrifugal patterns are shown here. Nascent fibrinogen (upper, normal; and lower, patient) gave $s^{\circ}{ }_{20}$, wate of 7.41 . Denatured fibrinogens in $5 \mathrm{M}$ guanidine $\cdot \mathrm{HCl}$ (upper, normal; and lower, patient) gave $s^{\circ}{ }_{20, w}$ rate of 6.45 . Cleaved fibrinogens in $5 \mathrm{M}$ guanidine $\cdot \mathrm{HCl}$ (upper, normal; and lower, patient) gave $:_{20, w}$ values of 2.27 and 2.26 , respectively. 


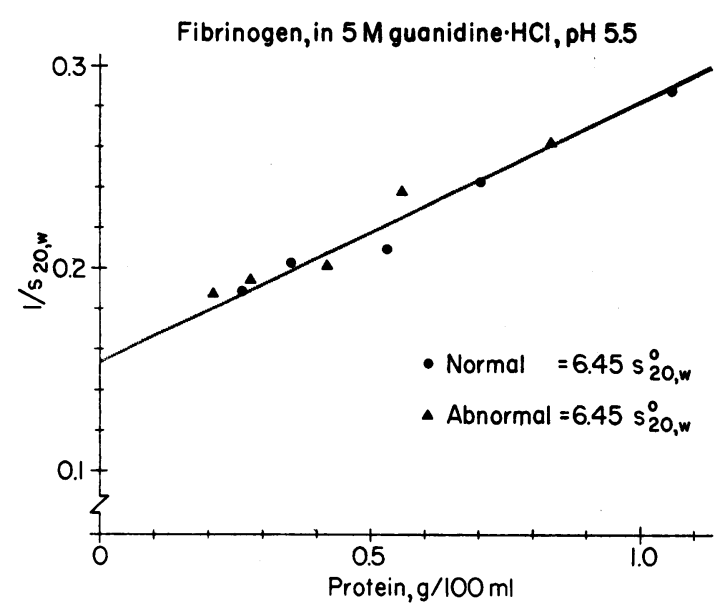

FIGURE 10 Reciprocal plots of $s$ rates of denatured fibrinogens in $5 \mathrm{M}$ guanidine $\cdot \mathrm{HCl}$ are shown here. Note the marked effect of concentration on $s$ rates.

concentration $\overline{\mathrm{M}}_{\boldsymbol{N}}$ average of 333,333 was determined for both fibrinogens.

$s^{\circ} \mathrm{x}, \mathrm{w}$ for both fibrinogens in $5 \mathrm{M}$ guanidine $\mathrm{HCl}$ were 6.45 (Fig. 10). After denaturation in $5 \mathrm{~m}$ guanidine $\mathrm{HCl}$

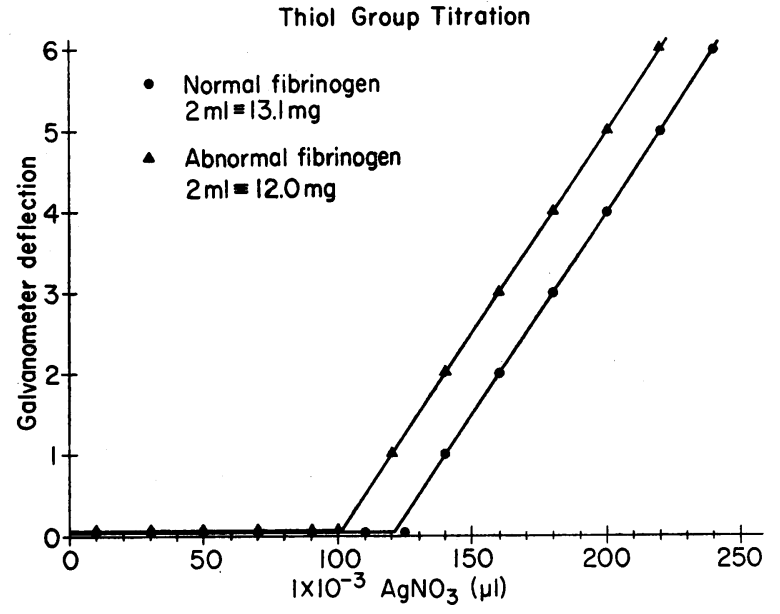

FIGURE 11 The titration curves for thiol groups in freshly purified fibrinogen samples with silver ions at room temperature in $1 \mathrm{~m}$ Tris buffer ( $\mathrm{pH} 7.4$ ), with platinum electrode, are shown in this figure.

and cleavage with sodium sulfite, $s^{\circ}{ }_{20, \pi}$ of 2.27 and 2.26 were obtained for normal and patient's fibrinogen, respectively. $\overline{\mathrm{M}}_{N}$ averages for these sulfitolysed fractions

TABLE V

Amino Acid Composition of Normal Human Fibrinogen and "Fibrinogen Detroit"

\begin{tabular}{|c|c|c|c|c|}
\hline \multirow[b]{3}{*}{ Amino acid } & \multicolumn{4}{|c|}{ Amino acid residues } \\
\hline & \multirow[b]{2}{*}{ "Fbg Detroit" } & \multirow[b]{2}{*}{ Normal } & \multicolumn{2}{|c|}{ Literature normal values } \\
\hline & & & $\begin{array}{c}\text { Blombäck } \\
\text { (61) }\end{array}$ & $\begin{array}{c}\text { Tristam } \\
\text { (62). }\end{array}$ \\
\hline & \multicolumn{4}{|c|}{$\%$ of $d r y w t$} \\
\hline Lysine & 6.07 & 8.01 & 8.14 & 9.2 \\
\hline Histidine & 2.51 & 3.09 & 2.28 & 2.6 \\
\hline Arginine & 7.63 & 9.81 & 7.38 & 7.8 \\
\hline Aspartic acid & 11.42 & 12.36 & 11.88 & 13.1 \\
\hline Threonine & 5.69 & 5.73 & 5.76 & 6.1 \\
\hline Serine & 6.50 & 6.60 & 5.85 & 7.0 \\
\hline Glutamic acid & 11.81 & 12.53 & 12.01 & 14.5 \\
\hline Proline & 4.19 & 4.88 & 4.47 & 5.7 \\
\hline Glycine & 5.11 & 5.29 & 4.74 & 5.6 \\
\hline Alanine & 3.03 & 3.21 & 2.61 & 3.7 \\
\hline Cystine/2 & 2.64 & 2.59 & 2.20 & 2.7 \\
\hline Valine & 3.80 & 4.97 & 4.38 & 4.1 \\
\hline Methionine & 2.42 & 2.54 & 1.94 & 2.6 \\
\hline Isoleucine & 3.66 & 4.09 & 4.13 & 4.8 \\
\hline Leucine & 5.96 & 3.86 & 5.62 & 7.1 \\
\hline Tyrosine & 4.64 & 3.08 & 4.77 & 5.5 \\
\hline Phenylalanine & 3.55 & 3.58 & 3.85 & 4.6 \\
\hline Glucosamine & 0.43 & 0.56 & - & - \\
\hline Galactosamine & 0.29 & 0.48 & - & - \\
\hline Total & $91.35 \%$ & $97.26 \%$ & $92.01 \%$ & $106.7 \%$ \\
\hline
\end{tabular}

Lysine, glucosamine, galactosamine, and possibly valine were decreased in "Fibrinogen Detroit," as compared to normal fibrinogen. 
TABLE VI

Carbohydrate Content of Fibrinogen in Per Cent

\begin{tabular}{lcccc}
\hline \multicolumn{1}{c}{ Samples } & $\begin{array}{c}\text { Protein-bound } \\
\text { hexose }\end{array}$ & $\begin{array}{c}\text { Sialic } \\
\text { acid }\end{array}$ & Hexosamine & $\begin{array}{c}\text { Total } \\
\text { carbohydrate } \\
\text { content }\end{array}$ \\
\hline Normal & 2.82 & 0.84 & 0.64 & 4.30 \\
Patient (P. H.) (Fibrinogen Detroit) & 1.77 & 0.65 & 0.49 & 2.91 \\
Normal values in literature (55, 63) & $3.2 \pm 0.3$ & $0.64-0.89$ & $0.5-0.6$ & $4.0-4.5$ \\
\hline
\end{tabular}

Protein-bound hexose, sialic acid and hexosamine were decreased in the patient's fibrinogen as compared to normal fibrinogen. Coefficient of variations for the different glycoproteins by the methods employed were as follows: protein-bound hexose, $4.5 \%$; sialic acid, $6.5 \%$; and hexosamine, $2.7 \%$.

were $57,707 \pm 4972$ (SD) and $54,685 \pm 2365$ (SD) for normal and patient's fibrinogen, respectively. U-V absorption spectra of both fibrinogens in $0.1 \mathrm{~m}$ potassium phosphate buffer, $\mathrm{pH} 7.0$, were identical and the absorption maxima was at $280 \mathrm{~m} \mu$. For denatured fibrinogens ( $5 \mathrm{M}$ guanidine $\mathrm{HCl}, \mathrm{pH} 5.5$ ) the absorption maxima was at $275 \mathrm{~m} \mu$.

Fig. 11 shows the curves for the amperometric titration of free $\mathrm{SH}$ groups in the two samples. Approximately 3 moles of free SH groups/mole of freshly prepared fibrinogen were found in both cases.

In Table $\mathrm{V}$ the amino acid composition of normal fibrinogen and "Fibrinogen Detroit" is listed. The values for lysine, glucosamine, galactosamine, and possibly valine were lower in the patient's fibrinogen, as compared to normal fibrinogen when all the reported values in the literature are also considered. Table VI reveals that the protein-bound hexoses, hexosamine, and sialic acid were decreased in the patient's fibrinogen.

The analysis of the $N$-terminal disulfide knot of normal and abnormal fibrinogen has been published (47) and, therefore, the results will be presented here only briefly. Fibrinopeptide A and B were released from normal as well as abnormal cyanogen bromide-cleaved fibrinogen when thrombin or trypsin was used (47). After reduction with mercaptoethanol and alkylation with iodoacetic acid, marked differences were noted in the abnormal fibrinogen when the tryptic digests of the alpha (A) chain were subjected to two-dimensional electrophoresis-chromatography on thin-layer cellulose plates. Whereas with normal fibrinogen all of the expected fragments of the alpha (A) chain could be accounted for, peptide No. 9 was absent in the tryptic digest of the abnormal fibrinogen (47). Further studies indicated that thrombin and trypsin had failed to cleave the alpha (A) chain of the abnormal fibrinogen between amino acids 19 and 20 and that No. 7 was composed of amino acids 17-23, rather than 20-23, as in normal fibrinogen (47). Final analysis revealed that arginine at the 19th position in the alpha (A) chain was replaced by serine.

\section{DISCUSSION}

Congenital bleeding disorders related to fibrinogen can occur as afibrinogenemia or hypofibrinogenemia and dysfibrinogenemia. Both diseases are rare, although afibrinogenemia seems to occur more frequently than dysfibrinogenemia (49). Whereas patients with afibrinogenemia usually suffer from severe spontaneous and posttraumatic hemorrhages (49), patients with dysfibrinogenemia may not necessarily display a bleeding tendency $(2,7,9)$. This may in part account for the fact that only seven families with dysfibrinogenemia have been described, with the seventh one in this report.

The plasma coagulation studies of our patient (P. H.) and her sister (Mo. H.) were very similar to those found in patients with congenital afibrinogenemia. If one had relied on fibrinogen determinations with the clotting procedure (21) only, a wrong diagnosis could have derived. It is interesting to note that one family with dysfibrinogenemia (8) was originally described as hypofibrinogenemia. Electrophoresis of the plasma proteins usually allows a differentiation between afibrinogenemia and dysfibrinogenemia, because in afibrinogenemia the fibrinogen is completely absent or the traces require a special immunoelectrophbretic technique (50). With turbidometric techniques or precipitation techniques one can always measure fibrinogen in plasma of patients with dysfibrinogenemia, but the amounts may be decreased $(1,2,5,8)$.

Whole blood of patients with afibrinogenemia is usually uncoagulable, whereas patients with dysfibrinogenemia may have normal $(5,7,8)$, slightly prolonged (2), or markedly prolonged (our patient) whole blood coagulation time. Only in one instance the patient's whole blood did not clot at all (1)

Congenitial afibrinogenemia has an autosomal recessive pattern of heredity, whereas in congenital dysfibrinogenemia the pattern is autosomal dominant $(5,8)$. This seems to be in agreement with our family studies. The nine children of $\mathrm{E}$. $\mathrm{H}$. came from three fathers, none of whom were available for studies (Fig. 12). In view of 


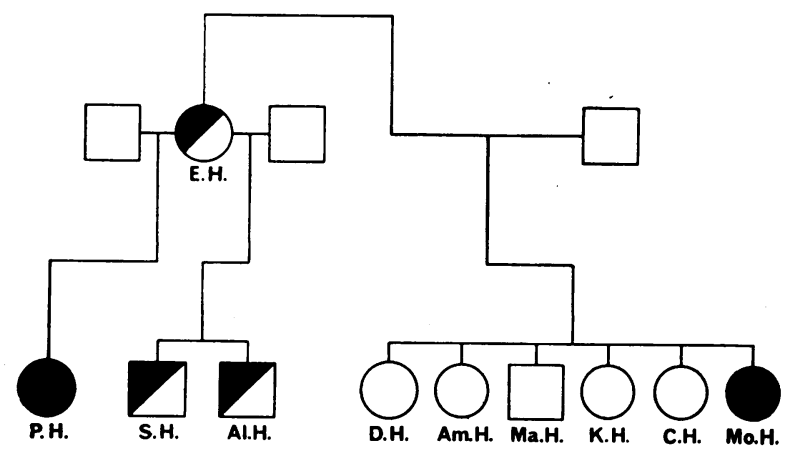

Figure 12 Family tree of the $H$ family. Open squares represent unaffected men; half-full squares, the two boys with only partially clottable fibrinogen. Open circles represent unaffected women; the two full circles are the two girls with totally abnormal fibrinogen molecules.

the fact that the mother is affected, that approximately one-half of her children are affected, and that it is unlikely that all three fathers had the same defective allele, the inheritance seems to be autosomal dominant.

In our patient $\mathrm{P} . \mathrm{H}$. and her relatives the fibrinolytic mechanism revealed no abnormality and fibrin-stabilizing enzyme (factor XIII) was normal. Similar results have been reported in other patients with dysfibrinogenemia $(2,5,7)$.

Prolonged plasma thrombin time seems to be a feature of most of the patients with dysfibrinogenemia $(2,5,7$, 8 ). However, prolonged thrombin time is also observed in states of hyperfibrinolysis, and, in particular, when fibrinogenolysis occurs. Under these conditions fibrinogen breakdown products competetively inhibit the conversion of intact fibrinogen molecules to fibrin by thrombin $(51,52)$. Moreover, the polymerization of the fibrin monomers is inhibited by these split products (5254). These fibrinogen fragments can be quantitatively determined by immunologic techniques in the patients' sera (23). Although the amount of fibrinogen-related molecules in the serum of our patient P. H. exceeded normal levels, it seems unlikely that these represented fibrinolytic products. Since the abnormal fibrinogen of P. H. responded slowly to thrombin, most of these molecules probably remained in the "so-called" serum to react with antifibrinogen in the quantitative precipitin test.

Determination of fibrinogen by several techniques revealed that only the levels of clottable fibrinogen were markedly decreased in the plasma of three other family members, the mother (E. H.) and two brothers (S. H. and Al. H.). It was, however, unusual to find the grossly abnormal thrombin time associated with these fibrinogen levels. One explanation would be that abnormal fibrinogen molecules interfered with the clotting of normal fibrinogen molecules. This assumption seems to be supported by the observation that thrombin time of normal plasma was inhibited by the addition of our patient's (P. H.) plasma and that thrombin clotting time of purified normal fibrinogen was delayed by the addition of her plasma (Table II). From these one might assume that the clotting disturbance in the abnormal fibrinogen lies in a defective polymerization of the fibrin monomers, rather than a defective release of either one or both of the fibrinopeptides A and B. This inhibitory effect of plasma of patients with dysfibrinogenemia on thrombin clotting time of normal plasma or fibrinogen has been observed previously by other investigators $(2,7)$, but "Fibrinogen Baltimore" does not show this effect (5).

The Detroit family expressed certain unique immunologic qualities, but this family also bore some relationships to both Cleveland and Baltimore families. All shared some common antigenic determinants with one another and with both, normal plasma fibrinogen and purified fibrinogen. The members of the Detroit family who did not exhibit coagulation difficulties formed the most compact immune complexes. The entire Detroit family had prominent faster mobility fibrinogen-related molecules on immunoelectrophoresis than did either the Cleveland or Baltimore patients. Thus, the Detroit fibrinogen has either a broader spectrum of charged molecules, or these are different in size from normal, or both changes could account for the faster mobility. Inheritance of the fibrinogen abnormalities from the Detroit mother seems clear, as all family members show changes from normal that differ only in respect to degree. In contrast, the fibrinogen defect in the Cleveland family may be traceable to the father as the mother shared the immunologic features with normals. The Cleveland son and daughter resembled one another immunologically, with their defective fibrinogens sharing some features with both the Detroit and Baltimore dysfibrinogenemias. Clearly, all of these families have some immunologically "normal" fibrinogen molecules. The families' interrelationship with one another and with normals may depend on the amount of normal fibrinogen each possesses. Also, the fibrinogen defect in one of the families may provide steric hindrence or mask an antigenic determinant group (reactive site) to account for the described changes in reactivity toward antinormal fibrinogen. The possibility of possession of antigenic determinant groups unique for each family can only be revealed by further study of the families once three separate antifibrinogens are prepared from the fibrinogen of each of the most affected patients.

The molecular weight of "Fibrinogen Detroit" under the conditions of our experiments was determined to be within the range of the reported values for normal human fibrinogen (55). Fibrinogen has three different $N$-terminal residues and the presence of three pairs of chains in the molecule, with the possibility of a dimer 
structure, has been suggested (56). Previous studies for the presence of subunits in bovine fibrinogen were carried out in $6 \mathrm{M}$ urea in which the molecule is only partially unfolded (56). Johnson and Mihalyi (38) have used $5 \mathrm{M}$ guanidine $\mathrm{HCl}$ for complete unfolding of the bovine fibrinogen molecule. Our studies in human fibrinogen were carried out in $5 \mathrm{M}$ guanidine $\mathrm{HCl}$, so that the presence of subunits should be certainly revealed in this solvent. However, the completely unfolded molecule of both the normal and the patient's fibrinogen sedimented in one single peak. Since only one component was present, one could conclude that either the molecule did not dissociate in this solvent, or that it dissociated into particles of equal weight. In the latter case, the largest possible particles would have been halves of the original molecule. Therefore, the observation that the apparent molecular weight in the approach to sedimentation-equilibrium studies was steeply rising above the half-molecular weight level provides a proof, in conjunction with the sedimentation-velocity studies, that fibrinogen did not dissociate in the concentrated guanidine solution. The sedimentation of fibrinogen in $5 \mathrm{~m}$ guanidine $\mathrm{HCl}$ was markedly affected by concentration, making the extrapolation of the sedimentation vs. concentration curve to infinite dilution very unreliable. This difficulty was circumvented by the reciprocal plots, as shown in Fig. 11 that was linear.

The sulfite-cleaved fibrinogen also appeared to be homogeneous, as shown in the sedimentation diagram (Fig. 9), suggesting that the chains are of the same weight as one another. Most evidence in the literature indicate that normal bovine fibrinogen consists of six polypeptide chains of approximataely $56,000 \mathrm{~mol}$ wt (56). Our results in the human are similar to the reported values, and these lie within the range of experimental errors. There was no evidence of subunits being loosely associated by noncovalent bonds. The polypeptides appear to be interlinked by disulfide bridges into a single unit.

The possible importance of the sulfur-containing groups in the different steps of blood coagulation has been considered in the past. It was suggested that the fibrinogen-fibrin conversion consisted of an aggregation of fibrinogen molecules due to the oxidation of their sulfhydryl groups and the formation of intermolecular disulfide bonds (57), but no free $\mathrm{SH}$ groups could be demonstrated by various investigators (58). Recently, however, Khomenko and Belitser (59) have demonstrated the presence of from 2 to 4 moles of free $\mathrm{SH}$ groups/mole of fibrinogen. Our results are similar to those of Khomenko and Belitser (59). The failure to titrate free $\mathrm{SH}$ groups in the fibrinogen molecule by various investigators could be due to the fact that they can only be determined in freshly prepared samples. Our titration was accomplished within $4 \mathrm{hr}$ of blood collection from the subjects. We also failed to titrate free $\mathrm{SH}$ groups in stored fibrinogen preparations.

Our studies have documented a specific molecular defect in the alpha (A) chain in the $N$-terminal disulfide knot of "Fibrinogen Detroit," in which arginine at the 19th position has apparently been replaced by serine (47). Our studies also revealed a decreased carbohydrate content of "Fibrinogen Detroit." According to Laki and Mester (60), an intact carbohydrate moiety is essential for polymerization of fibrin monomers and clot formation. The carbohydrates are apparently attached to the aspartic acid in the 52 nd position from the $N$-terminal end of the gamma chain. ${ }^{8}$ Although no definite information is available concerning the sites of disulfide bridges in the $N$-terminal knot of the fibrinogen molecule, it seems possible that due to the primary defective amino acid substitution in the alpha (A) chain, a secondary effect on the molecular configuration may have taken place, resulting in the unavailability of binding sites for the carbohydrate in the gamma chain. The replacement of a strongly basic amino acid with a neutral hydroxy acid in the $N$-terminal portion of the alpha (A) chain may result in considerable conformational changes in the $N$-terminal disulfide knot of fibrinogen that could affect the "active site" for polymerization (46). Inasmuch as the susceptibility of the No. 16 arginyl bond towards the action of thrombin was not altered by the substitution, at least in the cyanogen bromide-treated fibrinogen, it is likely that the polymerizaion stage that follows the release of the fibrinopeptide A was affected adversely, resulting in a severe bleeding disorder. The decreased lysine content in "Fibrinogen Detroit" may have been due to an incomplete hydrolysis of the protein, inasmuch as the hydrolysis was carried out for only $22 \mathrm{hr}$.

\section{ACKNOWLEDGMENTS}

We wish to thank Mr. George Gundlach and Mrs. Virginia Bray for their technical help.

This work was supported in part by U. S. Public Health Service grants HE 08309, HE 04712 and A.M 08142 and the Detroit General Hospital Research Corporation.

\section{REFERENCES}

1. Imperato, C., and A. G. Dettori. 1958. Ipofibrinogenemia congenita con fibrinoastenia. Helv. Paed. Acta. 13: 380.

2. Ménaché, D. 1964. Constitutional and familial abnormal fibrinogen. Thrombos. Diathes. Haemorrh. Suppl. 13: 173.

3. Beck, E. A. 1964. Abnormal fibrinogen (Fibrinogen "Baltimore") as a cause of a familial hemorrhagic disorder. Blood. 24: 853.

4. Beck, E. A., P. Charache, and D. P. Jackson. 1965. A new inherited coagulation disorder caused by an abnor-

${ }^{8}$ Blombäck, B., and M. Blombäck. Personal communication. 
mal fibrinogen (Fibrinogen Baltimore). Nature (London). 208: 143.

5. Jackson, D. P., E. A. Beck, and P. Charache. 1965. Congenital disorders of fibrinogen. Fed. Proc. 24: No. 4, 816.

6. Beck, E. A., M. W. Mosesson, P. Charache, and D. P. Jackson. 1966. Hämorrhagische Diathese mit dominantem Erbgang, verursacht durch ein anomales Fibrinogen (Fibrinogen Baltimore). Schweiz. Med. Wochschr. 96: 1196.

7. von Felten, A., F. Duckert and P. Frick. 1965. Gerinnungsstörung ohne hämorrhagische Diathese infolge verzögerter Aggregation der Fibrinogenmoleküle. Schweiz. Med. Wochschr. 95: 1453.

8. Hasselback. R., R. B. Marion and J. W. Thomas. 1963. Congenital hypofibrinogenemia in five members of a family. Canad. Med. Ass. J. 88: 19.

9. Forman, B., M. H. Boyer, and O. D. Ratnoff. 1967. A hereditary defect in the coagulation of fibrinogen by thrombin: studies on a family with Fibrinogen Cleveland. 10th Annual Meeting of the American Society of Hematology, Toronto.

10. Lee, R. I., and P. D. White. 1913. A clinical study of the coagulation time of blood. Amer. J. Med. Sci. 145: 495.

11. Tocantins, L. M. 1936. The bleeding time. Am. J. Clin. Path. 6: 160.

12. Brecher, G., and E. P. Cronkite. 1964. Estimation of the number of platelets by phase microscopy. In Blood Coagulation, Hemorrhage, and Thrombosis. L. M. Tocantins and L. Kazal, editors. Grune and Stratton, New York. 52.

13. Howell, W. H. 1914. The condition of the blood in hemophilia, thrombosis and purpura. Arch. Int. Med. 13: 76.

14. Langdell, R. D., R. H. Wagner, and K. M. Brinkhous. 1953. Effect of antihemophilic factor on one-stage clotting tests. J. Lab. Clin. Med. 41: 637.

15. Quick, A. J. 1940. The thromboplastin reagent for the determination of prothrombin. Science. 92: 112.

16. Ingram, G. I. C., and M. O. Matchett. 1960. The serial thrombin time method for measuring fibrinogenolytic activity of plasma. Nature (London). 188: 674.

17. Ware, A. G., and W. H. Seegers. 1949. Two-stage procedure for the quantitative determination of prothrombin concentration. Am. J. Clin. Path. 19: 471.

18. Ware, A. G., and W. H. Seegers. 1948. Plasma accelerator globulin: partial purification, quantitative determination, and properties. J. Biol. Chem. 172: 699.

19. Langdell, R. D., R. H. Wagner, and K. M. Brinkhous. 1964. Estimation of antihemophilic activity by the partial thromboplastin time technic. In Blood Coagulation, Hemorrhage and Thrombosis. L. M. Tocantins and L. Kazal, editors. Grune and Stratton, New York. 107.

20. Seegers, W. H., K. D. Miller. E. B. Andrews, and R. C. Murphy. 1952. Fundamental interactions and the effect of storage, ether, adsorbents and blood clotting on plasma antithrombin activity. Amer. J. Physiol. 169: 700.

21. Ware, A. G., M. M. Guest, and W. H. Seegers. 1947. Fibrinogen: with special reference to its preparation and certain properties of the product. Arch. Biochem. 13: 231 .

22. Fowell, A. H. 1955. Turbidometric method of fibrinogen assay. Amer. J. Clin. Path. 25: 340.

23. Barnhart, M. I. 1967. Immunochemistry. In Blood Clotting Enzymology. W. H. Seegers, editor. Academic Press Inc., New York. 266.

24. Seegers, W. H., J. F. Johnson and C. Fell. 1954. An antithrombin reaction related to prothrombin activation. Amer. J. Physiol. 176: 97.

25. Buckell, M. 1958. The effect of citrate on euglobulin methods of estimating fibrinolytic activity. J. Clin. Path. 11: 403.

26. Guest, M. M. 1954. Profibrinolysin, antifibrinolysin, fibrinogen and urine fibrinolytic factors in the human subject. J. Clin. Invest. 33: 1553.

27. Guest, M. M., B. M. Daly, A. G. Ware, and W. H. Seegers. 1948. A study of antifibrinolysin activity in the plasma of various animal species. J. Clin. Invest. 6: 785.

28. Beller, F. K., F. Koch, and E. F. Mammen. 1956. Thrombelastographische Untersuchungen bei isolierten Störungen der Vor- und 1. Phase der Gerinnung. Blut. 2: 112 .

29. Barnhart, M. I., G. F. Anderson, and W. J. Baker. 1962. Immunochemical studies on proteins important in blood coagulation. Thromb. Diath. Haemorrhagica. 8: 21.

30. Barnhart, M. I. 1968. Immunologic techniques. In Thrombosis and Bleeding Disorders-A Laboratory Manual. N. U. Bang, F. K. Beller, E. Deutsch, and E. F. Mammen, editors. Academic Press Inc., New York. In press.

31. Goodman, M., H. R. Wolfe, and S. Norton. 1951. Precipitin production in chickens. Study VI: Effect of varying concentrations of $\mathrm{NaCl}$ on precipitate formation. J. Immunol. 66: 225 .

32. Heidelberger, M., and F. E. Kendall. 1932. Quantitative studies on precipitin; determination of small amounts of a specific polysaccharide. J. Exp. Med. 55: 555.

33. Schultze, H. E., and G. Schwick. 1959. Quantitative immunologische Bestimmung von Plasmaproteinen. Clin. Chim. Acta. $4: 15$.

34. Grabar, P., and C. A. Williams. 1953. Méthode permettant l'étude conjuguée des propriétés électrophorétiques et immunochimiques d'um mélange de protéines. Application au sérum sanguin. Biochim. Biophys. Acta. 10: 193.

35. Wilson, M. W., and B. H. Pringle. 1954. Experimental studies of the agar plate precipitin test of Ouchterlony. J. Immunol. 73: 232.

36. Trautman, R. 1956. Operating and comparating procedures in analytical ultracentrifugation. J. Physiol. Chem. 60: 1211

37. Yphantis, D. A. 1964. Equilibrium ultracentrifugation of dilute solutions. Biochemistry. 3: 297.

38. Johnson, P., and E. Mihalyi. 1965. Physicochemical studies of bovine fibrinogen. I. Molecular weight and hydrodynamic properties of fibrinogen and fibrinogen cleaved by sulfite in $5 \mathrm{M}$ guanidine $\cdot \mathrm{HCl}$ solution. Biochim. Biophys. Acta. 102: 467.

39. Benesch, R., and R. E. Benesch. 1962. Determination of $\mathrm{SH}$ groups in proteins. In Methods of Biochemical Analysis. D. Glick, editor, Interscience Publishers, Inc., New York. 10: 43.

40. Prasad, A. S., L. Tranchida, D. Oberleas, and M. D. Poulik. 1967. Studies in macrocryoglobulinemia: Possible role of SH groups in cryoprecipitation. J. Lab. Clin. Med. 69: 456 .

41. Spackman, D. H., W. H. Stein, and S. Moore. 1958. Automatic recording apparatus for use in the chromatography of amino acids. Anal. Chem. 30: 1190.

42. Mokrasch, L. C. 1954. Analysis of hexose phosphates and sugar mixtures with the anthrone reagent. J. Biol. Chem. 208: 55

43. Rimington, C. 1940. Seromucoid and the bound carbohydrate of the serum proteins. Biochem. J. 34: 931. 
44. Ayala, W., L. V. Moore, and E. L. Hess. 1951. The purple color reaction given by diphenylamine reagent. I. With normal and rheumatic fever sera. J. Clin. Invest. 30: 781.

45. Hawk, P. B., B. L. Oser, and W. H. Summerson. 1951. Practical physiological chemistry. Maple Press Co., York, $\mathrm{Pa}$. 12th edition. 814.

46. Blombäck, B., M. Blombäck, B. Hessel, and S. Iwanaga. 1967. Structure of $N$-terminal fragments of fibrinogen and specificity of thrombin. Nature. 215: 1445.

47. Blombäck, M., B. Blombäck, E. F. Mammen, and A. S. Prasad. 1968. Fibrinogen Detroit-A molecular defect in the $N$-terminal disulfide knot of human fibrinogen. Nature. 218: 134

48. Blombäck, B., M. Blombäck, P. Edman, and B. Hessel. 1966. Human fibrinopeptides, isolation, characterization and structure. Biochim. Biophys. Acta. 115: 371.

49. Mammen, E. F. 1967. Irregular blood coagulation. In Blood Clotting Enzymology. W. H. Seegers, editor. Academic Press Inc., New York. 421.

50. Gross, R., G. Schwick, N. Lang, D. Nies, B. Rahn, M. Becker, and H. Hengstmann. 1963. Untersuchungen an einer angeborenen Afibrogenämie. Klin. Wchschr. 41: 695.

51. Triantaphyllopoulos, D. C. 1959. Nature of the thrombininhibiting effect of incubated fibrinogen. Am. J. Physiol. 197: 575 .

52. Alkjaersig, N., A. P. Fletcher, and S. Sherry. 1962. Pathogenesis of the coagulation defect developing during pathological plasma proteolytic ("Fibrinolytic") states. II. The significance, mechanism and consequence of defective fibrin polymerization. J. Clin. Invest. 41: 917.
53. Triantaphyllopoulos, D. C. 1961. Anticoagulant action of TAMe and AFIF. Amer. J. Physiol. 200: 771.

54. Latallo, Z. S., A. Z. Budzyński, B. Lipiński, and E. Kowalski. 1964. Inhibition of thrombin and of fibrin polymerization, two activities derived from plasmindigested fibrinogen. Nature (London). 203: 1184.

55. Harmison, C. R., and E. F. Mammen. 1967. Molecular characteristics of substances active in blood coagulation. In Blood Clotting Enzymology. W. H. Seegers, editor, Academic Press Inc., New York. 23.

56. Henschen, A. 1963. S. sulfo-derivatives of fibrinogen and fibrin: preparations and general properties. Arkiv Kemi. 22: 1 .

57. Lyons, R. N. 1945. Thiol-vitamin $\mathrm{K}$ mechanism in clotting of fibrinogen. Aust. J. Exper. Biol. Med. Sci. 23: 131.

58. Henschen, A. 1962. On the preparation and properties of sulfitolysed fibrinogen and fibrin. Acta Chemica Scand. 16: 1037.

59. Khomenko, O. K., and V. O. Belitser. 1964. Rupture of fibrinogen disulfide bonds by cysteine. Ukrayinśki Biokhimichnyi Zhurnal. 36: 22.

60. Laki, K., and L. Mester. 1962. The role of carbohydrate moiety in bovine fibrinogen. Biochim. Biophys. Acta. 57: 152.

61. Blombäck, B. 1967. Fibrinogen to fibrin transformation. In Blood Clotting Enzymology. W. H. Seegers, editor, Academic Press Inc., New York. 69.

62. Tristam, G. R. 1949. Amino acid composition of purified proteins. Adv. Protein Chem. 5: 83.

63. Szara, S., and D. Bagdy. 1953. On the polysaccharides of fibrinogen and fibrin. Biochim. Biophys. Acta. 11: 313. 